\title{
STUDENTS' EXPERIENCES OF HUMAN-CENTRED INTERVENTIONS IN A DESIGN EDUCATION SETTING
}

\author{
K. A. Chmela-Jones
}

Visual Arts and Design Department

Vaal University of Technology

Vanderbijlpark, South Africa

e-mail: kate@vut.ac.za

\section{ABSTRACT}

International and national developments in graphic design practice have incorporated unprecedented levels of engagement with end-user clients and audiences. However, instructional graphic design courses for undergraduates have not kept pace with this trend or with associated professional practice expectations. Traditionally, graphic design practice relies on the "expert", autocratic knowledge of the designer regarding the expected outcomes of the design brief. The use of co-operative tools and techniques such as human-centred design (HCD) enables the process to become a more democratic co-creation experience, where the client participants actively contribute to the development of the final design product. To prepare students for the new relationship between designers and end-users, newly developed HCD project interventions were created as part of the Communication Design modules offered in the third year Graphic Design Diploma programme at a University of Technology in South Africa. This article reports on two human-centred interventions in different settings and involving different types of stakeholders, with a view to analysing the experiences of students as they conducted the projects to assess the viability of the HCD projects towards establishing a proposed new curriculum that incorporates aspects of $\mathrm{HCD}$ as a fundamental approach to graphic design practice.

Keywords: graphic design education, human-centred, participation and co-design, student experience

\section{INTRODUCTION}

Design, including graphic design, is increasingly engaging in creating outcomes such as various design artefacts that serve the needs of audiences in a socially responsible and sustainable way. This is significantly different from "traditional" graphic design practice that focuses on developing design solutions for clients based solely on the "expert" knowledge of the designer and the limitations of the client's brief. It is inevitable that designers work for financial reward, therefore their priorities are governed by tasks that are profitable (Boehnert 2014) rather than socially responsible. To answer the mandate of South Africa's Department of Higher Education (DHET), with its focus on improving "the quality of teaching and learning throughout the system and, in particular to ensure that curricula are responsive to the national and regional 
context" (DoE 1997, 27), the graphic design curriculum at the University of Technology where the study took place includes design projects that respond to the social needs of society through the inclusion of participatory project interventions rooted in the principles of human-centred design (HCD). This direct contribution of members of society as co-creators, beneficiaries and audiences of graphic design products further responds to the Education White Paper 3, "A Programme for the Transformation of Higher Education" (DoE 1997), whose proposed community outcomes of higher education included addressing "the development needs of society" and "the problems and challenges of the broader African context" (DoE 1997, 1.3, $1.4)$.

The inclusion of socially motivated projects and methods, such as HCD, may motivate students to become "agents of change" within society and, according to Harding and Cowling (2006), it is this demographic that possesses the motivation to become the new generation of civic leaders. Methods such as HCD enable the development of design solutions for social inadequacies that affect communities. HCD has been described as a "usability process" (Staszewski 2017) but the democratic co-creative participation within HCD enables all stakeholders to have equal access to final decision making regarding their identified design needs. However, the challenges of applying a Western construct such as HCD to a South African environment must also be considered. Nevertheless, approaches based on the consideration of end-users such as user-centred, participatory design and aspects of HCD have been used to solve community-based design problems in various design disciplines in the Global South for a number of years. This aspect of social involvement, as applied through HCD methods, has generated positive change through design in countries such as India and China where it has empowered the inhabitants to contribute to the generation of solutions for their own problems (Urban and Kujinga 2017, 246). This study contributes to literature that calls for additional research regarding the application of people-centred design methods and the development of specific methodologies in non-Western contexts (Hussain 2007) as well as serves to inform design educators who are ultimately responsible for the development of relevant curricula.

\section{PROJECT OBJECTIVES}

Two human-centred projects (Intervention A and Intervention B) engaged 28 third-year graphic design students in the role of designers and community and institutional stakeholders. The specific objectives were:

- to investigate the feasibility of incorporating $\mathrm{HCD}$ and participatory design practices 
within a graphic design curriculum at a University of Technology;

- to design and implement four human-centred design project interventions, two of which are discussed in this article; and

- to investigate the experiences of graphic design students as they engaged in the HCD processes.

The two-part Intervention project investigated the experiences of graphic design students as they engaged in HCD processes in two different settings, involving different stakeholders, with a view to use the emergent data to inform the way in which HCD projects may be incorporated into pedagogical content in future. Intervention A applied HCD processes to eight small-scale case studies by investigating the needs of client participants in a nearby community in the development of commercial design artefacts with the aim of improving the clients' visual representation in the community. Intervention B applied HCD processes to a large-scale study in an institutional setting by investigating the needs of end-users of the participating University of Technology's Library and Information Services, in which not only the library users but the student designers themselves were stakeholders and beneficiaries. Focus group discussions and project reflection were used to gather information about the students' experiences at the end of each project and the data were analysed thematically.

\section{HCD AND GRAPHIC DESIGN}

The concept of HCD initially emerged to enable ease-of-use in the field of human-computer interaction (HCI) through the understanding that "design is a humanistic enterprise" (Harrison 2012, 57). HCD stresses the importance of understanding the needs of the people for whom the design artefact is intended and for this reason involves end-users throughout the design conceptualisation and development process. Thus, by employing methods of co-design, HCD enables end-users - who are viewed as "experts" of their own experience (Chisholm 2011) - to participate in the development of creative solutions to design problems and so fundamentally changes the power relationships between stakeholders in the design process (Voorberg, Bekkers and Tummers 2014, 2). Participatory approaches to design all aim to create meaningful change through the inclusion of non-experienced (i.e. not experts in design practice) participants in the design process (Sanders and Westerlund 2011, 1). Through co-creation end-users add value to the final design outcome and consequently contribute positively to some aspects of social responsibility required of graphic design projects. This article contends that if HCD approaches are a fundamental component and philosophy that underpins graphic design education, future graduates will be more likely to consider aspects of HCD in their practice. Notable design 
academics including Richard Buchanan (2001) and Klaus Krippendorff (2006) endorsed the human-centred approach by arguing that designers need to focus on work that takes in the entirety of the complex human experience through a focus on the needs, expectations and satisfaction of all stakeholders in the project as opposed to the sole needs of the client.

The implementation of HCD principles in the design process depends on the design specialisation of the stakeholders involved. For example, writing against a background in communication design, Jorge Frascara $(2007,213)$ stresses that the goal of visual communication is to change the attitude of users and thereby influence their behaviour, and $(2007,213)$ advocates for social responsibility in graphic design through the consideration of users in the design process. Steen $(2011,52)$ summarises HCD as founded on four key principles of engaging with end-users: to better understand their practices, needs, and preferences; to explore a fitting distribution of functions between people and technology; to establish project iterations in conducting the research required in generating and evaluating solutions; and to organise multidisciplinary teamwork HCD and the democratisation of the design process through practices like participative and co-design embraced by a number of international organisations (i.e. IDEO 2013) and design schools such as the one at Stanford University in the United States. Many design programmes now include aspects of HCD or related topics such as citizenship education in design in their curricula. Consequently, HCD and its related practices is discussed by educators at design conferences but few programmes (if any) have included this approach as fundamental to graphic design education at undergraduate level. In order to address the issues of transformation in the graphic design process that positively impact society, practices like HCD should become a priority for South African design educators.

South African graphic design industry must consider trends in international design practice as it requires designers to work in multi-disciplinary teams on international campaigns. Industry role players are keen on showcasing their commitment to sustainable and social projects even if these do not form part of their core business. Traditionally, the industry is based on a consumerist system that considers the needs of the client first with the needs of the endusers often being overlooked. The graphic design industry, therefore, must also consider societal, cultural and environmental challenges in society to develop into an occupation that forefronts transformation and social change.

Nevertheless, according to Taffe (2013), the design literature confirms that professional graphic designers criticise the co-creation process, as evidenced by HCD as "risking mediocre design" artefacts. Boehnert $(2014,119)$ further claims that design agencies are instrumental in leading designers towards the (commonly commercial) primary concerns of the design industry. 
According to Boehnert (2014) professional designers often engage with several projects simultaneously, during whose implementation the pressures of deadlines make it difficult to incorporate time-consuming HCD research methods and participatory processes to improve the focus on the needs of the client and end-user. In addition, logistical limitations (including resources, transportation, time management, channels of communication, or community access) within design industries could impede efforts of social consideration and community engagement in participatory design projects such as those involving HCD (Barnes and Du Preez 2015). Common industry practices such as the consideration of projects based on their commercial value affect how design educators perceive what needs to be taught and how much emphasis on social concerns and related design research methods is placed in undergraduate design programmes.

Although some South African design education institutions (for example, the University of Johannesburg and Stellenbosch University) may be embracing human-centred practices and social responsibility as a component of their curricula, a deeper engagement with these aspects at an undergraduate level and by more graphic design higher education providers may be necessary before change is reflected as part of standard industry practice.

\section{HCD IN CONTEXT OF SOUTH AFRICAN HIGHER EDUCATION}

Locally, in training South African graphic designers, Joubert and Economou $(2009,99)$ call for the "cultivation of a personal value system" in students to facilitate the implementation of what they term "sustainable design" in graduates. According to Moalosi, Rapitsenyane and M'Rithaa $(2010,813)$, the need to incorporate and appreciate mindfulness of social and ethical issues as well as responsible design practices in higher education (HE) design curricula is well on its way to being established. It is important to note that graphic design tuition is founded in vocational training and was situated mostly within the now defunct Technikon system. The focus, thus, of "traditional" graphic design education, the vestiges of which may still be found at some HE institutions, focused on training how to use the "tools" of graphic design rather than on the theoretical foundations and their applications to practice.

The 2015 \#FeesMustFall campaign shed light on the consideration of decolonised contexts, indigenous knowledge, social development, university/school readiness and language disparity within South African HE that had previously not been sufficiently addressed and implemented. South African design curricula are founded on a Western theoretical tradition and frequently omit to include local knowledge or traditions elsewhere in the Global South. Grosfoguel $(2007,214)$ states that this reliance on Western knowledge traditions is frequently interpreted by students, as "a hierarchy of superior and inferior knowledge and, thus, of superior 
and inferior people". In order to address this issue at the University of Technology involved in this study, for example, an increasing emphasis is made on teaching the history of design with an underpinning in local human perspectives, the inclusion of traditional concepts such as Ubuntu with many of the practical projects focused on creating design solutions to real-world problems in the local community. Bearing in mind the impact of the Western tradition on graphic design it is important for South African design educators to consider their teaching approaches to make the learning content relevant to students from multiple (mostly African) cultures and backgrounds.

\section{METHOD}

According to Hanington (2005), HCD research may require methods that are more "human" in their approach than impersonal means sometimes used in other ethnographic approaches to data collection, such as questionnaires. He suggests that observation is an appropriate tool for HCD research, as design development occurs in people-centred contexts requiring innovative and participatory methods that result in creative engagement and design artefacts. The IDEO (2013) (www.designkit.org/) toolkit employed as a tool in this study relies on people interaction and observation to generate data.

The HCD process requires close collaboration between designer and client, the sharing of ideas and experiences, and the collaborative framing of design solutions. Adequate preparation of materials and supporting artefacts by the project facilitator ensures that all stakeholders involved in the HCD process can participate equally and meaningfully. For this reason, the IDEO toolkit utilising the three HCD lenses of feasibility, desirability and viability that define the needs of the end-users, as well as what is technically viable and financially feasible was selected as the most appropriate tool for the implementation of HCD within the projects in this study. The IDEO toolkit is a tool that, through participant interactions, enables the designer to discover meanings, needs and desires via verbal or non-verbal means such as the development of prototypes that respond to the needs of audiences who do not traditionally think of themselves as designers (Kimbell 2012. It enables the design of an original artefact through participatory practice and co-creation and thereafter to obtain on-the-spot responses from clients on the prospective design solution (Von Hippel 2001).

\section{Project design and procedure}

The projects required students to work within the real-world setting of the local community and identify possible design problems that could benefit from an HCD intervention. For both projects named Intervention $\mathrm{A}$ and Intervention $\mathrm{B}$, students, under the supervision of the 
facilitator, conceptualised and designed comprehensive four- to six-week-long iterative design briefs using the HCD process as described in the IDEO toolkit. These briefs incorporated their project aims and objectives, client-related demonstrations and discussions, and research activities in the light of the assessment criteria and deliverables that would form part of the pedagogic process. Furthermore, the facilitator considered constructivist teaching and learning principles within the HCD process. To enable effective student-end-user collaborations to take place, a variety of structured, semi-structured and co-operative activities were proposed by the project facilitator.

The methods used in the research design enabled the facilitator to validate the results and contextualise human-centred design within the real-life setting of the University of Technology and nearby community by supplementing and contributing to the collected data. An important constituent of the Interventions A and B was the opportunity provided for experiential learning to take place whilst students engaged with the various client participants/end-users. In this way the Interventions may contribute to supporting ways of assimilating social dimensions into pedagogical settings within HE graphic design curricula. Although graphic design artefacts were an important component of the assessment criteria of the final outcomes of the Interventions, the focus of them was on the way in which the HCD process may be incorporated within the context of graphic design education.

\section{DATA COLLECTION, SAMPLING AND PROJECT OUTLINE}

Intervention A and B took place at a University of Technology in 2015 and 2016 as part of set student projects within the curriculum. Data were collected by the facilitator as well as by the participating students themselves during the course of the Interventions by means of observation, client consultation as proposed by the IDEO toolkit in the form of one-on-one or focus group interviews and student project journals. The IDEO toolkit emphasises an ethnographic approach to data collection with a focus on observational and interview methods as well as the study of documents. The resultant data also included transcribed semi-structured interviews conducted by students with the clients and the resultant design artefacts designed by the students in conjunction with the client, which both provided crucial learning opportunities for the students. In the case of the Interventions the final design artefacts produced by the participating students and community members were considered documents under study, which formed a part of the total data analysis.

Non-probability purposive and convenience sampling was used. A total of 28 third-year Communication Design students were invited to participate in Intervention $A$ in the first semester of 2015. Four students chose not to participate. Intervention B took place in the first 
semester of 2016 and involved nine members of the same group of students.

Of the students who chose to participate in the project 11 were female, 13 male. The community stakeholders (Intervention A - external small-scale interaction with community members in local area, Intervention B - internal large-scale interaction with the participating University of Technology community stakeholders within its own library) contributed to the data through stakeholder interviews that influenced the design artefacts developed in Interventions $\mathrm{A}$ and $\mathrm{B}$. In the case of Intervention A, identified businesses with which the student would collaborate in developing design artefacts were located close to the university. In Intervention B, the participants, VUT Library users were selected based on their availability and willingness to take part in the study.

In the case of Intervention A, all project briefs and supplementary information were available in English as the language of instruction at the participating University of Technology. Intervention A involved interactions among the facilitator, the participating third-year graphic design students and the community stakeholders chosen by the students and was conducted in the community stakeholder's chosen language (it was found that most of the community stakeholders were happy to converse in English as the students were working in multicultural groups). Intervention B was based at the participating University of Technology and was therefore conducted in English.

\section{INTERVENTION A}

Intervention A required participating students to identify their own (community based) client, complete a needs analysis based on HCD processes as outlined by IDEO, and, together with the facilitator, develop a design brief based on participatory, co-design criteria that delivered solutions to suit the client's needs. Students were allowed to work in small self-selected collaborative groups and most chose to work in groups of two or three. Although this approach has been criticised as less successful in developing effective learning opportunities than the alternative in which the group is selected by a project coordinator (Enerson 1997), the logistics of the inquiry (that included off-campus data collection, transport and security issues and dealing with unknown community stakeholders) made it appropriate.

As part of Intervention A, graphic design students had to identify a potential client within their community and worked collaboratively with that client in developing commercial artefacts that corresponded to the client's needs. A set of standard assessment criteria for design projects was included in the project launch and was used in the final assessment of the design artefacts. Intervention A resulted in 8 completed collaborative design artefacts that ranged from the redesign of existing corporate identities for community businesses to a more holistic project that 
designed a new portable workstation for an informal cobbler. The project utilised all three recommended IDEO phases (Hear/Create/Deliver) at different stages of the Intervention process. It involved the students working collaboratively in groups of two or three, liaising with their chosen community participant (in the role of client - Hear) and finally developing (Create) a potential commercial design artefact for the client which developed (Deliver) out of a humancentred, participatory process. The students employed self-reporting/documentation methods as well as brainstorming techniques utilising basic tools such as post-it notes, markers and paper to inspire collaboration and ideation with the end-users, namely, the community participants. These rudimentary tools are common to HCD practice and stimulate roleplaying and playful participation that encourages collaboration and ideation (Brown 2009, 87). Di Russo (2016, 131) believes that utilising this kind of amateur-type method in HCD type projects results in collaborative visual identities that are "more playful, open and non-judgemental" than those resulting from traditional methods of data collection. Each design artefact was unique as each student submitted their entire "process book" including all project data (participant selection, planning, interview and meeting information whereby each participant had distinctive, individual needs). One of the goals of the project was for the students to experience the strategic design process outside the standard pedagogic setting of the university. The students together with the community participants developed design solutions ranging from a fresh take on a carwash drive-through, the development of a portable informal cobbler workstation, several new corporate identities and a revamped corporate identity for a doctor's surgery. Although some of the projects may seem small-scale, each made a significant difference, benefiting not only to the community participant end-users but also the students through the experience of providing solutions to real-world design problems.

Throughout the process the students engaged in feedback and reflection sessions with the facilitator as well as with their chosen community participants. They took place once a week mostly in the form of an informal discussion during class time and involved all participating students. On occasion, students would approach the facilitator outside of class time to get advice on the way forward in developing viable design solutions. The students were expected to share their experiences of the project with the rest of the class. To contribute to this process data involving the community participants/end-users were captured using audio recordings and written field notes and those participants that had no objection were photographed. Additionally, to document the interactions between participating students and community members, students were encouraged to utilise self-reporting/self-documentation methods such as photographic documentation of the process as well as reflect on the process in a project diary. Self-reporting methods such as project diaries and their own photographic documentation is 
seen as a "participant-led" method of data collection that supports the general gathering of data but the choice of what data is gathered is open to the interpretation of the participants (Hagen 2011). The resultant documents and images contributed to the shared reflection in class. The students' experiences of the project were commented on by their peers as well as the facilitator and enabled them to make appropriate adjustments to the final designs before getting feedback from the community participants. In the following stage, participating students were encouraged to utilise creative material generated by the end-users in the development of the final design solutions to make them feel valued and to generate a "shared design language" (Sanders and Westerlund 2011) in developing solutions that answered the criteria as set by the design briefs reflective of the needs of the community participants. The comments of community participants and students during their interactions of the design artefacts at the development stage of the design solution were generally positive. However, it was noticed that a number of the participants were hesitant to offer divergent views or critiques on the design proposed by the students, a perspective supported by Di Russo $(2016,182)$ who states that a positive culture such as the one experienced in collaborative environments and HCD projects creates a high degree of support but a low degree of critical thinking. Students reported varying degrees of constructive criticism or feedback from peers with many supporting existing concepts rather than actively offering novel ideas or collaborating on developing new ones. Hence the success of this Intervention differed from group to group. It was observed that some students embraced the participatory, co-design aspects of the project while others (a minority) found this component of the project challenging and reverted to tried-and-tested methods of client and designer interaction that refrain from including the stakeholders at each stage of the design development.

The emphasis of the design artefacts developed by the participants of Intervention A was not on the commercial potential of the project but rather on the social interaction and learning benefits for the students as well as the determination of the feasibility of including this type of project within a graphic design curriculum.

\section{Findings: Intervention A}

At the onset of the project all the third-year students in the graphic design programme were willing to participate, but ultimately four chose not to complete the assignment. The students chose the participating clients so it was presumed that the final developed design artefacts would differ from group to group as each individual brief was based on the client's needs. In the focus group interviews where students reflected on the Intervention, most students participating in Intervention A emphasised the positive community engagement created by the 
interaction with the participants. However, it soon became evident that the documentation and self-reflection aspect of the project varied vastly in terms of engagement from participant to participant. The expectation of the students was that the self-reporting aspect of the intervention would assist in providing rich visual data in the form of photographs or proposal drawings from the participating community members. This was at times not the case as four of the community members would cite a lack of ability or knowledge when asked to contribute to visual representations. To help solve this problem, but still to benefit from the community members' expertise, the students relied on self-generated moodboards and scamps as supplementary visual aids during meetings with community members rather than on visual representations generated by the community members themselves. Moreover, the majority of the visual material (e.g. photographs) generated by the student participants themselves was of poor quality, possibly due to a lack of familiarity with the photographic process itself or inadequacies in the photographic applications (apps) available on their cellphones, on which many students relied. It soon became evident to most participating students that owing to the generative and co-design nature of Intervention A the final outcome of the project might not meet all traditional assessment criteria as required by a traditional design brief. This supports Taffe's (2013) findings of design practitioners' perceptions of participatory projects resulting in sub-standard design artefacts. Several students attempted a more laborious and time-consuming design artefact development process by scheduling additional consultations with the end-users, resulting in some stronger design solutions. This approach, however, depended on the availability and willingness of the end-users to attend additional meetings and consultations with the student designers. The evident tension between the willingness and expertise of the student designer and the availability of the community stakeholder/participant must be considered when developing HCD based projects. Although the assessment criteria for the intervention project was adjusted to accommodate shared experiences and expertise many students found it difficult to adjust their expectations of the final design artefact to meet the new criteria. The students had the option to withdraw from the Intervention at any time and/or not to submit the final project artefact for grading, although all participating students chose to complete the project and to include it as a component of their final portfolio.

\section{INTERVENTION B}

Intervention B built on the students' experiences in Intervention A but applied the concept of a participatory HCD project to a large-scale institutional context. They had to investigate the needs of the university library users and develop design artefacts based on the ones perceived by the students as being most urgent. According to Taffe $(2015,50)$, a paradox exists in co- 
design, participatory projects where designers offer their design expertise and end-users their contextual knowledge. Normally, these two "camps" remain separate, but in Intervention B the participating graphic design students acted in the role of researchers, design "experts" and library users.

The student's interviews were mostly limited to including other library users as most library staff members were reluctant to participate in the project. It was foreseen that this knowledge, together with the previous familiarity with HCD briefs gained in Intervention A would have assisted the students in completing Intervention B in the allocated time (4 weeks). To explore the various HCD mediations necessary in the participating University of Technology Library and Information services, the first step in Intervention B was obtaining permission from the Manager of Technical Services of the library to conduct the study there. Once permission was obtained and the support of the various library heads of departments assured, the participating students could freely interact with the library users and within the library space to ascertain what its needs and shortcomings were. Nine fourth year graphic design participating students chose to work alone or in groups of three. Three students were female and six were male. A short questionnaire was developed to determine the most urgent needs of library users and was used to assist in the focus group interviews that took place before the design proposals were developed. Although a number of issues highlighted by the results of the questionnaire, such as a confusing layout and lack of effective signage were found to be problematic, the library's existing awkward wayfinding system was highlighted as the issue that made it difficult for most participatory end-users in the study to utilise the library effectively.

All graphic design student participants chose to address the issue of wayfinding by developing their design solutions co-creatively with a number of other library users, which were then submitted to the library's manager of technical services for comment. The solutions ranged from a colour-coded wayfinding system based on the participating University of Technology's existing faculty colours to an interactive app that could be used as a walk-through within the space. Once the Intervention was completed the students submitted their entire "process books" including all project data (participant selection, planning, questionnaire results as well as interview and meeting information) and followed up by a reflection debriefing meeting to solicit as accurate a representation of their experience as possible. Although positively received by the library staff, lack of available funding prevented any of the solutions from being implemented.

\section{Findings: Intervention B}

Participating students mentioned, positively, the ethnographic data collection aspect of the Intervention: "[t]he interviews were enjoyable and informative, I was able to get an idea of the 
changes the students would like to see being implemented at the library" (respondent LM) and "Interestingly, collecting data was the most enjoyable. Hearing what issues people face and their different, at times, and similar views on a subject was good to see" (respondent TK). All the student participants agreed that being library users themselves gave them insight into how they approached formulating the final design solution (IDEO = Create). In terms of differing from previous HCD projects they may have engaged with in the past, students expressed surprise at the lack of commitment and interest in the project from library staff who, in their opinion, were expected to have demonstrated more "buy-in" in terms of the project (respondent WT).

\section{Summary of the Intervention findings}

Intervention A highlighted the following issues that students struggled with in the application of the HCD process: they perceived commitment problems among community stakeholders (in the role of clients); and they expressed frustration with the "loose" structure of the clientdesigner interaction, given the importance of time management in design projects. They recognised the tensions that sometimes relate to poor design decisions resulting from the cocreation aspect of HCD projects, when it became apparent that community stakeholders had very specific ideas of what they wanted their final design solutions to look like. Intervention B took place at the participating University of Technology's Library and Information Services building. By this time, following the experience of Intervention A, the participating students had confidence in determining the needs of library users considering their own experiences and by asking effective questions of other library users. They found that non-designer library users frequently had needs relating to the library that differed from their own. The library's director as the key participant-client in the process received a report on the needs of the library users but given her institutional responsibilities she was unavailable to participate in the desired HCD co-creation process to develop solutions for the identified issues.

Intervention A emphasises the lessons learned for professional practice experience in small-scale HCD case studies where the interactions are limited to a designer and community stakeholder. Intervention B highlighted the implementation on HCD processes in a large-scale institutional setting where the student designers were also stakeholders and beneficiaries of the process. Both Interventions highlight some of the issues that arise when a commercially developed process such as HCD is implemented in an education setting and the subsequent lessons learned provide a basis for the development of a reconsidered graphic design curriculum. Although the assessment criteria for the intervention project was adjusted to accommodate shared experiences and expertise, many students found it difficult to adjust their 
expectations of the final outcome to meet the new criteria that considered the participation of non-expert participants in the development of the final design artefact.

\section{RECOMMENDATIONS AND CONCLUSION}

HCD processes are seldom applied at undergraduate level in graphic design programmes at South African higher education institutions. The findings of the Interventions A and B confirm that tensions arise when (student) designers work with non-designer participants on co-creation, collaborative projects such as those commonly found in HCD practice. It could be deduced that in an education setting HCD projects work better in smaller, more experienced groups such as with postgraduate students who choose to specialise in the application of this method. Nevertheless, it is recommended that in order to develop competency in the methods involved for HCD projects the introduction of HCD theories and closely supervised limited processes could be introduced at undergraduate level. The Interventions reported on in this study highlight emerging issues regarding end-user engagement that may need to be considered when applying HCD processes within design curricula as part of an undergraduate programme in graphic design.

\section{REFERENCES}

Barnes, V. and V. du Preez. 2015. Mapping empathy and ethics in the design process. Proceedings of DEFSA Ethics and accountability in Design: Do they matter? 1-4 September. Midrand Graduate Institute, Midrand. South Africa.

Buchanan, R. 2001. The problem of character in design education: Liberal arts and professional specialization. International Journal of Technology and Design Education 11(1): 13-26.

Boehnert, J. 2014. Design vs. The design industry. Design Philosophy Papers 12(2): 119-136.

Brown, T. 2009. Change by design: How design thinking transforms organizations and inspires innovation. New York: Harper Business.

Chisholm, J. 2011. What is user-centred design? Design for Europe. http://designforeurope.eu/what-codesign (Accessed 11 May 2015).

Department of Education. 1997. A programme for the transformation of higher education. Education White Paper 3. Pretoria, 24 July 1997. https://che.ac.za/sites/default/files/publications/ WhitePaper3.pdf

DoE see Department of Education.

Di Russo, S. 2016. Understanding the behaviour of design thinking in complex environments. Ph.D. Thesis. Swinburne University of Technology, Melbourne, Australia.

Enerson, M. D. 1997. The Penn State Teachers II. Pennsylvania University Park, the Pennsylvania State University.

Frascara, J. 2007. Bad words in design education. Design Issues 23(4): 62-68.

Grosfoguel, R. 2007. The epistemic decolonial turn. Cultural Studies 21(2): 211-223.

Hagen, P. 2011. A practice-based study of social technologies in early design research. Ph.D. thesis. University of Technology Sydney, Sydney, Australia. 
Hanington, B. M. 2005. Research education by design: Assessing the impact of pedagogy on practice. Paper presented at the Joining Forces conference, 22-24 September, University of Art and Design. Helsinki, Finland.

Harding, R. and M. Cowling. 2006. Social entrepreneurship monitor. London: London Business School.

Harrison, A. K. 2012. Wicked problems/Weak designs. PhD thesis. University of Sydney, Sydney, Australia.

Hussain, R. M. R. 2007. Problem-based learning in Asian Universities. Studies in Higher Education 32(6): 761-772.

IDEO team. 2013. Human-centered design (HCD) toolkit: Design thinking toolkit for social innovation project. $2^{\text {nd }}$ Edition. https://www.ideo.com/post/design-kit. (Accessed 14 March 2015).

Joubert, N. and I. Economou. 2009. Towards an educational strategy for promoting social, environmental and ethical awareness in visual communication education. Proceedings of the DEFSA conference, Graaf Reinet, South Africa, 4-5 November 2009.

Kimbell, L. 2012. Rethinking design thinking: Part II. Design and Culture 4(2): 129-148.

Krippendorff, K. 2006. The semantic turn: A new foundation for design. New York: Taylor \& Francis.

Moalosi, R., Y. Rapitsenyane and M. M'Rithaa. 2010. An analysis of sustainability issues in Southern African design institutions' programmes. Proceedings of Sustainability in Design: Now! LeNS Conference, 29 September to 1 October. Bangalore, India.

Sanders, E. and B. Westurland. 2011. Experiencing, exploring and experimenting in and with co-design spaces. Nordic Design Research Conference 2011, Helsinki. http://www.maketools.com/ articlespapers/SandersWesterlundNordes2011.pdf (Accessed 3 October 2015).

Staszewski, E. 2017. Why co-creation? We need democracy in democracies. http://www.demoshelsinki/ fi.en/2017/01/12/co-creation and democracy (Accessed 4 June 2018).

Steen, M. 2011. Tensions in human-centred design. CoDesign: International Journal of CoCreation in Design and the Arts (7)1: 45-60.

Taffe, S. 2013. Undesigning graphic design: Facilitating the artist in everyone, inter-discipline. The Art Association of Australia and New Zealand Annual Conference, (AAANZ 2013), Melbourne, Australia. 7-9 December 2013.

Taffe, S. 2015. The hybrid designer/end-user: Revealing paradoxes in co-design. Design Studies 40: 3959.

Urban, B. and L. Kujinga. 2017. The institutional environment and social entrepreneurship intentions. International Journal of Entrepreneurial Behaviour \& Research 23(4). http://researchgate.net/ publication/315341603_The_institutional_environment_and_social_entrepreneurship_intentions (Accessed 6 August 2017).

Von Hippel, E. 1988. The sources of innovation. New York and Oxford: Oxford University Press.

Voorberg, W. H., V. J. J. M. Bekkers and L. G. Tummers. 2014. A systematic review of co-creation and co-production: Embarking on the social innovation journey. Public Management Review: 1-25. 